\title{
Farmers' Knowledge on Climate Change Effects in Agriculture
}

\author{
Md. Saiful Islam, Muhammad Humayun Kabir, Md. Sekender Ali, Mst. Sharmin Sultana, \\ Mohammad Mahasin
}

Department of Agricultural Extension and Information System, Sher-e-Bangla Agricultural University, Dhaka, Bangladesh

Email: *mhumayunsau@gmail.com

How to cite this paper: Islam, Md.S., Kabir, M.H., Ali, Md.S., Sultana, Mst.S. and Mahasin, M. (2019) Farmers' Knowledge on Climate Change Effects in Agriculture. Agricultural Sciences, 10, 386-394. https://doi.org/10.4236/as.2019.103031

Received: November 24, 2018

Accepted: March 24, 2019

Published: March 27, 2019

Copyright () 2019 by author(s) and Scientific Research Publishing Inc. This work is licensed under the Creative Commons Attribution International License (CC BY 4.0).

http://creativecommons.org/licenses/by/4.0/

\section{c) (i) Open Access}

\begin{abstract}
The major objectives of the study were to determine farmers' knowledge on climate change effects in agriculture and to identify the factors that influenced farmers' knowledge on climate change effects in agriculture. The study was conducted in four villages under Kazipur upazila of Sirajgonj district. Data were collected by using interview schedule from randomly selected 113 respondents during $1^{\text {st }}$ January to $30^{\text {th }}$ January, 2018. The findings revealed that an overwhelming majority $(78.8 \%)$ of the respondents had medium to high knowledge on climate change effects in agriculture. Among eight selected characteristics, extension media contact, training received, organizational participation, and cosmopoliteness had significant positive contribution to the farmers' knowledge on climate change effects in agriculture. It is recommended that to increase farmers' knowledge on climate change effects initiative should be taken to improve farmers' knowledge through more involving with organization, extension media and program.
\end{abstract}

\section{Keywords}

Farmers Knowledge, Climate Change, Agriculture, Bangladesh

\section{Introduction}

The climate of Bangladesh can be characterized by high temperatures, heavy rainfall, high humidity, and fairly marked three seasonal variations like hot summer, shrinking winter and medium to heavy rains during the rainy season. In general, maximum summer temperatures range between $38^{\circ} \mathrm{C}$ and $41^{\circ} \mathrm{C}$ (100.4 and $105.8^{\circ} \mathrm{F}$ ). April is the hottest month in most parts of the country. January is the coolest month, when the average temperature for most of the country is $16^{\circ} \mathrm{C}-20^{\circ} \mathrm{C}\left(61^{\circ} \mathrm{F}-68^{\circ} \mathrm{F}\right)$ during the day and around $10^{\circ} \mathrm{C}\left(50^{\circ} \mathrm{F}\right)$ at 
night. According to [1], due to climate change effect sea level in the coastal region of Bangladesh has been predicted to rise up to $80 \mathrm{~cm}$ by 2100. Climate change in Bangladesh has become a threat to the farmers' perception towards harmful effects of climate change on agriculture.

Both climate change and agriculture interrelated processes occur on a global scale. Agriculture influences climate change and climate change affects agricultural production. Global warming is projected to have significant impacts on conditions affecting agriculture including temperature, precipitation and glacial run-off. These conditions determine the carrying capacity of the biosphere to produce enough food for the human population and domestic animals. Reduction in crop yields in most tropical and sub-tropical regions will be due to decreased water availability and new or changed insect pest incidence. The agriculture sector is a driving force in the gas emissions. This occurs through clearing land for crop-production. Bangladesh climate change is considered one of the most serious threats to sustainable development with adverse impacts expected on the environment, human health, food security, economic activity, natural resources and physical infrastructure. Bangladesh also faces some adverse impacts on various aspects especially on agricultural sector. In some landfall areas of the country about 743,321 acres' crops were damaged fully and $1,730,316$ acres' crops were damaged partly in a severe cyclone storm of hurricane intensity in 2007 [2].

Rural areas are highly vulnerable to climate change, since people there depend heavily on natural resources such as local water supplies and agricultural land. In fact, about $70 \%$ of the population in developing countries live in rural areas, where agriculture is their main source of incomes [1]. Agriculture has been increasingly affected by climate variability and changes. The combination of a high level of poverty and a depleted ecological system increase the country's vulnerability to the impacts of climate change [3]. That is why the current study has been taken to determine the farmers' knowledge on climate change effects in agriculture.

In this context, the present study has been conducted with a view to the following objectives.

1) To describe some selected characteristics of the farmers;

2) To determine farmers' knowledge on climate change effects in agriculture;

3) To identify the factors that influence farmers' knowledge on climate change effects in agriculture.

\section{Methodology}

\subsection{Study Area}

The study was conducted at Kazipur Upazila under Sirajgong district of Bangladesh where people were affected by climate change especially flood. Mainly floods affected farmers were considered as sample of this study. As a locale to the proposed study, two unions namely, Maizbari and Natuarpara under Kazipur 
Upazila of Sirajgonj district were selected purposively. Four villages from both unions were selected randomly as the locale of the study.

\subsection{Population and Sampling}

The Researcher himself with the help of Upazila Agriculture Officer, Local leaders and concerned Sub-Assistant Agriculture Officer (SAAO) was collected an updated list of population of the study. The total numbers of farm families head in the selected villages were 1293. According to Yamane's [4] formula, sample size was 113 at $9 \%$ precision level, 50\% degree of variability and the value of the standard normal variable $(Z)=1.96$ at $95 \%$ confidence level. The given formula is stated as:

$$
n==\frac{Z^{2} P(1-P) N}{Z^{2} P(1-P)+N e^{2}}
$$

where, $n=$ sample size;

$N=$ population size;

$e=$ the level of precision;

$Z=$ the value of the standard normal variable given the chosen confidence level (e.g. $Z=1.96$ with a confidence level $95 \%$ );

$P=$ the proportion or degree of variability.

The sample was then selected from the four villages by considering proportionate random sampling procedure. A reserve list of 12 farm families head (about $10 \%$ of the sample) was kept purposively if any respondent was unavailable at the time of data collection. The final data were collected during $1^{\text {st }}$ January to $30^{\text {th }}$ January, 2018. The distribution of population and sample was shown in Table 1.

\subsection{Selection and Measurement of Variables}

In a descriptive social research, selection and measurement of the variable is a momentous task. An organized research usually contains at least two identical elements viz. independent variable and dependent variable. Considering study nature, location of study, time and other logistic support, we selected farmers' eight characteristics/independent variables for analysis of the study. These are Age, Educational background, Farm size, Annual family income, Organizational participation, Agricultural extension contact, Training exposure and Cosmopoliteness. On the other hand, the dependent variable of the study was farmers' knowledge on climate change effects in agriculture. The measurement techniques of both independent and dependent variables are discussed as follows.

\subsubsection{Measurement of Independent Variables}

Age of the farmers was measured in terms of actual years from his birth to the time of interview. Level of education was measured as the ability of an in individual respondent to read and write or the formal education received up to a certain standard. It was expressed in terms of year of schooling. Farm size of the 
Table 1. Distribution of population and sample of farmers of the selected villages.

\begin{tabular}{ccccc}
\hline Name of the unions & Name of the villages & Population & Sample size & Reserve list \\
\hline \multirow{2}{*}{ Maizbari } & Paikortoli & 308 & 26 & 3 \\
& Salavora & 342 & 30 & 3 \\
\multirow{3}{*}{ Natuarpara } & Natuarpara & 316 & 28 & 3 \\
& Ghoragacha & 327 & 29 & 3 \\
& Total & 1293 & 113 & 12 \\
\hline
\end{tabular}

respondents was measured as the size of his farm on which he continued his farm practices during the period of the study. Annual family income indicates total earning of a farmer and the members of his family both from agriculture and other socially acceptable regular means such as business, service etc. It was expressed in thousands taka during the previous year. Training received was measured by total number of days of agricultural training received by the respondents' farmer in his/her life. Organizational participation of a respondent was measured by computing an organizational participation score according to his/her nature and duration of participation in five (5) selected different organizations up to the time of interview. The extension media contact of a respondent was measured on the basis of the response of the farmers against the extent of his using of selected seven media. Cosmopoliteness of a respondent was measured in terms of his nature of visits to the six (6) different places external to his own social system.

\subsubsection{Measurement of Dependent Variable}

Farmers' knowledge on climate change effects in agriculture was measured on 10 basic open ended questions. Each question contains 2 marks. Knowledge of rural farmers was determined by summing up the weights for their responses to all the ten questions. Thus farmers' knowledge on climate change effects in agriculture score could range from 0 to 20 , where zero (0) indicating no knowledge and 20 indicate highest knowledge.

\subsection{Collection and Processing of Data}

Data were collected by the researcher himself through face to face interview. A well-structured interview schedule (questionnaire) was developed based on the objectives of the study. The schedule contained both open form and closed form questions. The interview schedule was pre-tested with 20 farmers by the researcher. Necessary additions, corrections and modifications were made in the schedule on the basis of the pre-test results. Then final data were collected from the selected 113 farmers with using questionnaire. Questions were asked systematically and explanation was made whenever necessary. The respondents were interviewed at their leisure time so that they can give accurate information in a cool mind. To build rapport and motivation in the interview situations, the researcher endeavoured to provide conditions that maximum trust maintained 
each respondent's interest and minimized status difference. The final data were collected during 1 January to 30 January, 2018.

After completion of data collection, data were coded, compiled, tabulated and categorized according to the objectives of the study. The entire individual respondent's data were transferred into a master sheet for facilitating the required analysis. Local units were converted into standard units. In case of qualitative data, appropriate scoring technique was followed to convert the data into quantitative form.

\subsection{Analysis of Data}

Descriptive statistical measures, including number, percentage distribution, range, average, and standard deviation were used. To find out the contribution of identified characteristics on the farmers' knowledge on climate change effects in agriculture, multiple regression models was used.

The model used for this analysis can be explained as follows:

$$
Y_{i}=a+b_{1} x_{1}+b_{2} x_{2}+b_{3} x_{3}+b_{4} x_{4}+b_{5} x_{5}+b_{6} x_{6}+b_{7} x_{7}+b_{8} x_{8}+e
$$

where $Y_{i}$ is the farmers' knowledge on climate change effects in agriculture; $x_{1}$ is their age; $x_{2}$ is educational background; $x_{3}$ is organizational participation; $x_{4}$ is farm size; $x_{5}$ is annual household income; $x_{6}$ is training experience, $x_{7}$ is agricultural extension contact and $x_{8}$ is cosmopoliteness. $b_{1}, b_{2}, b_{3}, b_{4}, b_{5}, b_{6}, b_{7}$ and $b_{8}$ are regression coefficients of the corresponding independent variables, and " $\mathrm{e}$ " is random error, which is normally and independently distributed with zero (0) mean and constant variance.

\section{Results and Discussion}

\subsection{Selected Characteristics of the Farmers}

The salient features of the selected characteristics of the farmers like possible and observed range, number and percent distribution, mean, standard deviation and categorisation are presented in Table 2.

The majority (86.7\%) of the farmers were middle aged to old aged. About two-third $(71.7 \%)$ of them were primary to secondary level of education. Majority of the respondents had marginal to small farm size (92.9\%), low to medium annual family income (87.6\%) and no to low training received (73.5\%). Most of the farmers had no to low organizational participation (76.1\%), medium to high extension media contact (76.1\%), and low to medium cosmopoliteness (81.4\%).

\subsection{Farmers' Knowledge on Climate Change Effects in Agriculture}

The observed scores of knowledge of the respondents ranged from 12 to 18 against the possible range of $0-20$. The mean scores were 14.54 with the standard deviation of 1.58 respectively. On the basis of knowledge, farmers were classified into three categories such as, "low knowledge", "medium knowledge" and "high knowledge" on climate change. The distribution of the farmers 
Table 2. Distribution of the respondents according to their characteristics $(\mathrm{N}=113)$.

\begin{tabular}{|c|c|c|c|c|c|c|c|}
\hline \multirow{2}{*}{$\begin{array}{c}\text { Variables } \\
\text { (Measuring unit) }\end{array}$} & \multicolumn{2}{|c|}{ Range } & \multirow{2}{*}{ Categories } & \multicolumn{2}{|c|}{ Respondents } & \multirow{2}{*}{ Mean } & \multirow{2}{*}{ SD } \\
\hline & Possible & Observed & & Number & Percent & & \\
\hline \multirow{3}{*}{$\begin{array}{l}\text { Age } \\
\text { (Years) }\end{array}$} & \multirow{3}{*}{ - } & \multirow{3}{*}{$20-70$} & Young (up to 35) & 15 & 13.3 & \multirow{3}{*}{49.27} & \multirow{3}{*}{12.08} \\
\hline & & & Middle aged (36 - 50) & 50 & 44.2 & & \\
\hline & & & Old $(>50)$ & 48 & 42.5 & & \\
\hline \multirow{4}{*}{$\begin{array}{c}\text { Education } \\
\text { (Year of schooling) }\end{array}$} & \multirow{4}{*}{-} & \multirow{4}{*}{$0-15$} & Illiterate $(0-0.5)$ & 25 & 22.1 & \multirow{4}{*}{4.84} & \multirow{4}{*}{3.65} \\
\hline & & & Primary $(1-5)$ & 43 & 38.1 & & \\
\hline & & & Secondary $(6-10)$ & 38 & 33.6 & & \\
\hline & & & Above secondary $(>10)$ & 7 & 6.2 & & \\
\hline \multirow{3}{*}{$\begin{array}{l}\text { Farm size } \\
\text { (Hectare) }\end{array}$} & \multirow{3}{*}{ - } & \multirow{3}{*}{$0.09-2.16$} & Marginal $(0.02-0.20)$ & 26 & 23.0 & \multirow{3}{*}{0.42} & \multirow{3}{*}{0.33} \\
\hline & & & Small $(0.21-1.0)$ & 79 & 69.9 & & \\
\hline & & & Medium (>1.0) & 8 & 7.1 & & \\
\hline \multirow{3}{*}{$\begin{array}{c}\text { Annual family } \\
\text { income (“ } 000 \text { ” Taka) }\end{array}$} & \multirow{3}{*}{-} & \multirow{3}{*}{$46-531$} & Low (up to 177) & 73 & 64.6 & \multirow{3}{*}{175.42} & \multirow{3}{*}{121.26} \\
\hline & & & Medium $(>177-354)$ & 26 & 23.0 & & \\
\hline & & & High $(>354)$ & 14 & 12.4 & & \\
\hline \multirow{3}{*}{$\begin{array}{l}\text { Training received } \\
\text { (No. of days) }\end{array}$} & \multirow{3}{*}{-} & \multirow{3}{*}{$0-15$} & No (0) & 40 & 35.4 & \multirow{3}{*}{4.30} & \multirow{3}{*}{4.18} \\
\hline & & & Low $(1-7)$ & 43 & 38.1 & & \\
\hline & & & Medium (>7) & 30 & 26.5 & & \\
\hline & & & No $(0)$ & 40 & 35.4 & & \\
\hline Organizational & $0-15$ & $0-12$ & Low $(1-4)$ & 46 & 40.7 & 296 & 285 \\
\hline (Score) & & $0-12$ & Medium (5 - 8) & 25 & 22.1 & 2.90 & 2.85 \\
\hline & & & High $(>8)$ & 2 & 1.8 & & \\
\hline Extension media & & & Low (up to 13) & 27 & 23.9 & & \\
\hline contact & $0-28$ & $10-24$ & Medium (14 - 19) & 54 & 47.8 & 16.72 & 3.59 \\
\hline (Score) & & & High $(>19)$ & 32 & 28.3 & & \\
\hline Cosmonoliteness & & & Low (up to 11) & 30 & 23.0 & & \\
\hline (Score) & $0-21$ & $9-19$ & Medium (12 - 15) & 63 & 58.4 & 13.38 & 2.33 \\
\hline & & & High $(>15)$ & 21 & 18.6 & & \\
\hline
\end{tabular}

according to their knowledge on climate change effects in agriculture scores is shown in Table 3.

Findings revealed that the majority (46.1\%) of the respondents had medium knowledge on climate change while (32.7\%) and (21.2\%) having high and low knowledge categories respectively. From above, it can be said that, the respondents who have medium to high knowledge about effects of climate change on agriculture. However, still $21.2 \%$ farmers possess low knowledge on climate change which need to change or improved their knowledge level through taking various steps.

\subsection{The Contribution of the Selected Characteristics of the Respondents to Their Knowledge on Climate Change}

The contribution of the selected characteristics of the respondents to their knowledge on climate change on agriculture has been shown in Table 4. The table shows that only four characterises viz., extension media contact, training received, organizational participation, and cosmopoliteness were positive and significant contribution with their knowledge on climate change effects in agriculture. The remaining characteristics such as age, education, farm size and annual 
Table 3. Distribution of the farmers according to their knowledge on climate change effects in agriculture.

\begin{tabular}{ccccc}
\hline \multirow{2}{*}{ Categories } & \multicolumn{2}{c}{ Respondents' } & Mean & SD \\
\cline { 2 - 3 } & Number & Percent & & \\
\hline Low knowledge (up to 13) & 24 & 21.2 & & \\
Medium knowledge (14 - 15) & 52 & 46.1 & & 1.58 \\
High knowledge (above 15) & 37 & 32.7 & & \\
Total & 113 & 100 & & \\
\hline
\end{tabular}

Table 4. Multiple regression coefficients of the contributing variables related to the farmers' knowledge on climate change effects in agriculture.

\begin{tabular}{|c|c|c|c|c|c|c|}
\hline $\begin{array}{l}\text { Dependent } \\
\text { variable }\end{array}$ & $\begin{array}{l}\text { Independent } \\
\text { variable }\end{array}$ & $\beta$ & $\rho$ & $\mathbf{R}^{2}$ & Adj. $R^{2}$ & F \\
\hline \multirow{8}{*}{$\begin{array}{c}\text { Farmers' } \\
\text { Knowledge on } \\
\text { climate change } \\
\text { effects in } \\
\text { agriculture }\end{array}$} & Age & 0.097 & 0.295 & \multirow{8}{*}{0.481} & \multirow{8}{*}{0.441} & \multirow{8}{*}{12.04} \\
\hline & Education & 0.081 & 0.455 & & & \\
\hline & Farm size & -0.087 & 0.333 & & & \\
\hline & Annual family income & 0.035 & 0.713 & & & \\
\hline & Training received & 0.242 & $0.031^{*}$ & & & \\
\hline & $\begin{array}{l}\text { Organizational } \\
\text { participation }\end{array}$ & 0.229 & $0.038^{*}$ & & & \\
\hline & $\begin{array}{l}\text { Extension media } \\
\text { contact }\end{array}$ & 0.218 & $0.028^{*}$ & & & \\
\hline & Cosmopoliteness & 0.187 & $0.046^{*}$ & & & \\
\hline
\end{tabular}

family income have no significant contribution with their knowledge on climate change effects in agriculture.

Multiple regression analysis was computed to find out contributing independent variables of farmers knowledge on climate change effects in agriculture. All the 8 variables, when considered together, the predictability co-efficient $\left(\mathrm{R}^{2}\right)$ were 0.481 . This means that all the 8 variables put together would bring $48.1 \%$ variation of knowledge to their climate change effects in agriculture. Among these 8 variables, extension media contact, training received, organizational participation and cosmopoliteness showed positive and significant influence on farmers' knowledge on climate change in agriculture. The results indicated that a unit increase in extension media contact, training received, organizational participation and cosmopoliteness would results in $0.218,0.242,0.229$ and 0.187 units increase in the extent of farmer's knowledge on climate change effects in agriculture respectively. The F value was found significant. Hence, it may be concluded that the selection of analysis was appropriate.

From the analysis it is also indicated that extension media contact of the farmers was positive and significantly contributed (significant at $5 \%$ level, $\mathrm{p}<0.05$ ) with their knowledge on climate change effects in agriculture. It means that the more the extension media contact of the farmers is more their knowledge level on climate change effects in agriculture. Alternatively, it can be said that with the 
increase of extension media contact of the farmers will increase their knowledge on climate change effects in agriculture. The finding is similar with the studies of [5] [6] and [7].

Data presented in Table 4 revealed that training received of the farmers was positive and significantly contributed (significant at $5 \%$ level, $\mathrm{p}<0.05$ ) with their knowledge on climate change effects in agriculture. This finding indicated that farmers' have more training will increase the farmers' knowledge on climate change effects in agriculture. The finding is similar with the studies of [8] [9] and [10].

Data presented in Table 4 revealed that organizational participation of the farmers was positive and significantly contributed (significant at $5 \%$ level, $\mathrm{p}<$ 0.05 ) with their knowledge on climate change effects in agriculture. This finding indicated that farmers' have more organisational participation will increase the farmers' knowledge on climate change effects in agriculture. The finding is similar with the studies of [10] [11] and [12].

It was revealed from the analysis that cosmopoliteness of the farmers was positive and significantly contributed (significant at $5 \%$ level, $\mathrm{p}<0.05$ ) with their knowledge on climate change effects in agriculture. This finding means that increase of cosmopoliteness of the farmers will also increase their knowledge on climate change effects in agriculture. Cosmopoliteness helps farmers to improve knowledge-as which ultimately help them to take adaptation strategies. The finding is similar with the study of [12] and [13].

\section{Conclusion and Recommendations}

From the above findings and discussion it might be concluded that the overwhelming majority of the farmers' were medium to high knowledge on climate change effects in agriculture. Only few farmers had low knowledge on climate change effects in agriculture. Therefore, still there have scope to improve farmers' knowledge scenario through taking various steps. Extension media contact, training received, organizational participation and cosmopoliteness of the farmers were important in making more knowledge on climate change effects in agriculture. The result concluded establishment of more organization, more training facilities and farmers' involvement with those will increase farmers' knowledge on climate change effects in agriculture. Extension media contact also helped farmers to make more knowledge on climate change effects in agriculture. Therefore, the extension agents should increase their contact with the farmers. So, more training, meeting and demonstration program should be arranged in order to make more knowledge on climate change effects in agriculture. All these initiative probably will help the farmers to make high knowledge which ultimately helps them to take more adaptation strategies to minimize harmful effects of climate change in agriculture.

\section{Conflicts of Interest}

The authors declare no conflicts of interest regarding the publication of this paper. 


\section{References}

[1] IPCC (2007) Summary for Policy Makers. In: Solomon, S., Qin, D., Manning, M., Chen, Z., Marquis, M., Averyt, K.B., Tignor, M. and Miller, H.L., Eds., Climate Change 2007: The Physical Science Basis. Contribution of Working Group I to the Fourth Assessment Report of the Intergovernmental Panel on Climate Change, Cambridge University Press, Cambridge and New York, NY.

[2] BBS (2015) Bangladesh Bureau of Statistics, Statistical Division, Ministry of Planning, Government of the People's Republic of Bangladesh.

[3] Khan, et al. (2010) The Social Dimensions of Adaptation to Climate Change in Bangladesh. Development and Climate Change Discussion Paper No. 12. World Bank, Washington DC.

[4] Yamane, T. (1967) Statistics: An Introductory Analysis. 2nd Edition, Harper and Row, New York.

[5] Sharmin, H. (2005) Rural Women's Perception of Benefits of Involvement in Income Generating Activities under a Non-Government Organization. M.S. (Ag. Ext. Ed.) Thesis, Department of Agricultural Extension Education, Bangladesh Agricultural University, Mymensingh.

[6] Sayeed, M.A. (2003) Farmers' Perception of Benefit from Using Manure towards Integrated Nutrient Management (INM) for Sustainable Crop Production. M.S. (Ag. Ext. Ed.) Thesis, Department of Agricultural Extension Education, Bangladesh Agricultural University, Mymensingh.

[7] Kabir, M.T.N. (2002) Perception of Farmers on the Effects of Barind Integrated Area Development Project towards Environmental Upgradation. M.S. (Ag. Ext. Ed.) Thesis, Department of Agricultural Extension Education, Bangladesh Agricultural University, Mymensingh.

[8] Kabir, M.H. and Rainis, R. (2012) Farmers' Perception on the Adverse Effects of Pesticides on Environment: The Case of Bangladesh. International Journal of Sustainable Agriculture, 4, 25-32.

[9] Pal, B.K. (2009) The Perception of Organic Farmers Regarding Introduction of ICT in Organic Farming. M.S. (Ag. Ext. Ed.) Thesis, Department of Agricultural Extension Education, Bangladesh Agricultural University, Mymensingh.

[10] Uddin, M.N. (2004) Farmers' Perception of Sustainable Agriculture: A Comparative Study between CARE Beneficiaries and Non-beneficiaries. M.S. (Ag. Ext. Ed.) Thesis, Department of Agricultural Extension Education, Bangladesh Agricultural University, Mymensingh.

[11] Fardous, M.T. (2002) Farmers' Perception of Village and Farm Forestry Program towards Sustainable Forestry Development. M.S. (Ag. Ext. Ed.) Thesis, Department of Agricultural Extension Education, Bangladesh Agricultural University, Mymensingh.

[12] Alam, M.Z. (2001) Farmers' Perception of Binamoog-5 as a Summer Crop. M.S. (Ag. Ext. Ed.) Thesis, Department of Agricultural Extension Education, Bangladesh Agricultural University, Mymensingh.

[13] Hamid, et al. (1997) Climate Change Impacts on Agriculture and Food Security-Adaptation and Mitigation Options in National Policies and Strategies, Workshop Presentation. BCAS, Dhaka. 